\title{
1 A STRUGGLE FOR DEFINITION: EXPLANATORY MODELS OF SATANISM IN 2 SOCIOLOGY
}

5 Oxana Mikhaylova

6 HSE University, 101000, Moscow, Russia

7 oxanamikhailova@gmail.com

9 Abstract

10 Many terms used both in sociology and lay discourse have nonscientific origins. Therefore, it is

11 important to clarify the meanings of these concepts to understand the heuristic capacities that

12 they have for scientific research. The notion of satanism emerged in evangelical manuscripts,

13 and it has since appeared repeatedly in political and juridical discussions. Moreover, there are

14 conflicting opinions about the suitability of this notion for sociological study. In this paper, I use

15 critical concept analysis and a critical perspective on religion to examine sociological discourse

16 on satanism. I argue that to enhance sociology — and religious studies in general — among

17 contemporary views of satanism, the naturalist model is the most promising, but it is not the only

18 one that should be used to explain this notion.

\section{Keywords}

21 satanism, explanatory models, critical concept analysis, sociological discourse, naturalism 
25 "Satanism" has long been used in various secular and nonsecular contexts. It first emerged in 26 evangelist manuscripts (Frankfurter 2001), and it has appeared multiple times in political and

27 juridical discourses throughout history. Politicians and legal actors use this word every day, and

28 they include it in official governmental reports. However, there is considerable ambiguity in how

29 the concept of satanism is applied in the social sciences and related fields.

30 One well-known example of the struggle to define the concept is satanic moral panic

31 (Lewis 2016: 210). This phenomenon occurred in the USA and Europe in the 20th century.

32 During that period, many political and scientific actors believed in the existence of a huge secret

33 network of violent satanic cults that performed sacrifices and rituals with children. Various

34 groups debated the meaning of satanism. The mass media promoted that idea to increase ratings;

35 feminists used the narrative against satanism to show the exploitive nature of patriarchy;

36 evangelists fought against the decline in the number of Christian adepts, and psychotherapists,

37 detectives, and anti-cultists tried to influence the professionalization of their occupations.

38 Sociologists also served as experts and engaged in discussions (Bromley 1991). Considering the

39 nonscientific origin and the wide usage of this concept by the nonscholarly public, it remains

40 unclear whether this term is suitable as a theoretical notion in scientific discourse.

41 Taub and Nelson (1993) state that sociology, in comparison with crime reporting in the

42 media, mostly portrays satanism positively and creates the image of a "satanic establishment,"

43 Other researchers argue that "satanic studies" exist (Holt 2012). Furthermore, Petersen (2014)

44 identifies three modes of discourse in scientific studies of satanism ("de-demonization,

45 sanitization, and heterogenization"), and he argues about the constant boundary-work that occurs

46 within "satanic studies". Other authors are skeptical about the analytical capacities of "satanism." 
47 Granholm (2012), for instance, argues that "satanism" is an oppressive and marginalizing notion,

48 and he suggests using other terms such as "Postsatanism" and "Left-hand path." Looking at this debate, questions arise about the state of current sociological studies of

50 "satanism:" how do they portray it? Do they construct boundaries within and with lay discourse?

51 How are the different discourses related to each other, and is there any potential to develop new

52 analytical accounts? Therefore, in this article, I deconstruct the use of satanism in sociological

53 discourse to shed light on the controversial status of the term "satanism." Knowledge of the

54 debates about satanism in sociological discourse is crucial for developing new theoretical

55 accounts of satanism. Second, this paper provides the reasons that the concept is adopted and

56 applied in empirical studies. Third, this paper shows the capacities and limits of different models

57 of satanism, and it suggests ideas to improve the explanatory power of their accounts. Overall, I

58 hope to contribute to current scholarship on satanism by clarifying how "satanism" is used in

59 sociology. This examination is also important for religious studies, because I provide a method

60 for critical concept analysis that could, with some alterations, be used in other investigations ${ }^{1}$.

61 Also, as satanism is a concept used by many religious students as other than a sociological term,

62 the critical deconstruction in this paper could pave the way to reconsider how this concept is

63 applied in other subfields of religious studies. At the end of this manuscript, I introduce my

64 position on the place of this term in contemporary sociology of religion. Nevertheless, I think

65 that my argument is not the final point in the discussion of the place of satanism in contemporary 66 religious studies.

67 There have been many attempts to systematize the diverse academic scholarship on

68 satanism. Holt (2012), for instance, wrote a dissertation focused on "religious" satanism.

\footnotetext{
${ }^{1}$ It is important to notice that, although my analysis is inspired by the CRR, I do not fully follow the ideas of this perspective. Rather, my analysis is driven by that theoretical perspective.
} 
69 Although his work provides one picture of the scholarship on satanism, it does not include an

70 overview of "rationalist" and "reactive" satanism studies (I borrow these terms from Petersen

71 (2009)), which belong to nonreligious types of satanic discourse. The same critique applies to

72 Taub and Nelson (1993). Even though they investigated sociological scholarship, they viewed it

73 as a homogeneous field characterized by a mostly positive framing of satanism. Petersen (2014)

74 studied discourse in satanic scholarship, and he noted different types of satanism, but there was

75 no close examination of the field of sociology. White (2017) analyzed three major books on

76 satanism and provided several observations; however, other publications were not examined.

77 Introvigne (2016), Dyrendal et al. (2015), Van Luijk (2016), Faxneld (2017), and Granholm

78 (2012) proposed classifications of satanism scholarship. They were a preliminary step toward

79 proposing their own definitions of satanism, but they were not specifically intended as an

80 analysis of the sociological discourse on satanism. Ritzer et al. 2001: 114 called this "the

81 metatheoretical analysis metatheorizing as a prelude to theory development." This article, in

82 contrast, explores studies on all three types of satanism (rationalist, reactive and esoteric),

83 surveys them from the 1980s until 2018, and specifically explores sociological accounts of

84 satanism. It is necessary to investigate the three types of satanic discourses because they are

85 interrelated. For instance, a person can like metal music and practice religious satanism.

86 Therefore, excluding that type of discourse could create an incomplete picture of the sociological

87 discourse on satanism. I studied sociological discourse separately from discourses relating to

88 other social sciences because of the difference in the ontological, epistemological, and

89 methodological principles that form their foundations.

90 To answer the research questions and reveal the current state of sociological studies of

91 satanism, I use the perspective of the critical research on religion (CRR). CRR is a modern 
92 approach in religious studies that treats religion as an empty signifier (Berenskoetter 2017). In

93 this paper, I also see satanism as a notion that is socially constructed in different social and

94 historical contexts. In particular, the discourse on satanism by sociologists is investigated using

95 critical concept analysis (Berenskoetter 2017). I combine the optics of several researchers

96 (Fitzgerald and Goldstein, King, Boyarin) who use different CRR perspectives.

97 Fitzgerald argued that the word "religion" is used too broadly so his critical study of

98 religion involves deconstructing the "religious-secular" binary (Goldstein et al. 2016). He

99 distinguishes between critical religion and CRR (Fitzgerald 2015). Critical religion for Fitzgerald

100 is the genealogical study of religion and concepts that are connected to it. Looking at religion, he

101 claims it has two "faces:" one that is peaceful and not connected with power and the second

102 one - the barbarous one - that was constructed in the 17th century. The opposition between

103 Christians and Barbarians emerged when being Christian became required for citizenship.

104 Goldstein et al. (2016) assert that the role of critical religion studies is to understand the

105 structural mechanisms that reinforce power relations in society. They look not only at how

106 religion is formed through power relations but also at how religion strengthens power relations.

107 The goal of such an examination should not lie in acting either against or in favor of religion. I

108 contend that it is beneficial to connect CRR with other critical research perspectives, such as the

109 feminist tradition, because questioning religion leads to challenging intersecting concepts such as

110 gender, race, ethnicity, and mental health (Lynch 2017; Robinson 2019). Bearing in mind

111 Asprem's (2016) critique of CRR in deconstructing and not proposing fruitful alternatives, I tried

112 not only to deconstruct but also to suggest new ways to work with the concept. 
113 This article is structured as follows: First, I describe the method that was used to analyze

114 sociological discourse on satanism. Then I present the results of my deconstruction in detail. At

115 the end, I offer conclusions.

\section{Concept Analysis of Sociological Discourse on Satanism: Methodological Aspects}

117 My deconstruction involves a sequence of several steps (Table 1). First, the theories are divided

118 according to the models on which they are explicitly or implicitly based. Then, the terms

119 "theoretical conception" and "representatives" are added from the same meta-theoretical scheme.

120 After that, characteristics such as "country of origin" are incorporated to consider the cultural

121 factor of theory construction, and "basic terms" are used to illustrate the terminological apparatus

122 of each theory. Next, an additional dimension is included - "macromicro." These categories do

123 not mean the same thing as in Ritzer's (1975) classification of the metatheoretical accounts,

124 where the theory is classified as macro or micro. Rather, I follow the position of Berger et al.

125 (2018: 1284) that theories cannot be characterized as "macro" or "micro;" rather, such terms can

126 be applied only to their interpretations. This means that the binary opposition of "micro-macro"

127 does not apply to all objects of sociological investigation, and adaptation is needed for each of

128 them. Therefore, Ritzer's concept of "methods and means of data collection" was added to my

129 scheme. This dimension of classification shows the method typically employed by sociologists,

130 whose research belongs to a certain model. To enrich this concept, Abbot's (2004: 53-60)

131 typology of explanatory programs is used. The last part of my analysis is to construct a map of

132 the relations between the theories. For that purpose, I use the approach of Berger et al. (2018:

133 1607-1718) to allocate connections between theories. Those scholars outlined five types of

134 relations that could exist between theories: "elaboration," "integration," "competition,"

135 "variants," and "proliferation." 
After I present the methodological principles of my approach, I present the results of my

137 deconstruction.

1382 Explanatory Models of Satanism in Sociology

\subsection{Interpretative Models of Satanism}

141 This model has several distinguishing traits (Devyatko 1996: 52). Its proponents do not believe

142 that the social sciences and natural sciences can use the same methods of investigation. They

143 argue that social sciences deal with people who tend to imbue their actions with meaning, unlike

144 the objects of the natural sciences. Therefore, the explanatory mechanisms of the social sciences

145 should not be copied from the natural sciences. Finally, some argue that, to examine the

146 conscious behavior of people, the Verstehen approach should be used. This means that both

147 scientific and semantic definitions should be considered. A semantic definition, according to

148 Kaplan, makes something understandable to other people without necessarily relying on logical

149 principles. A scientific definition is based on strict logical rules that should help the explainer

150 formulate the pattern or law that describes the facts.

151 In the interpretative approach, satanism is represented in the theories of moral panic,

152 social problem construction, dark tourism, and authority in satanic communities. I classified

153 these theories as interpretative because, in all of them, satanism is understood as a social

154 construct. Studies of this type have mostly been conducted in the USA, Great Britain, and

155 Scandinavian countries. Satanism in interpretative sociology is explored both as a macro- and as

156 a micro-phenomenon. In the following sections, I show the origins of each theory and the ideas

157 that underlie them. 


\subsubsection{Macrointerpretative Sociological Models of Satanism}

The term "moral panic" was proposed by Stanley Cohen, although not in connection with satanism and satanic studies. The co-occurrence of the terms "satanism" and "moral panic" started with US scholars, who tried to explain the gossip about satanic ritual abuse in sects in the USA and Europe (Cree et al. 2015). Fundamentalists, psychiatrists, cultural feminists, self-help groups, neoconservatives, and police workers were involved in spreading moral panic. Their actions resulted in many juridical cases against people who were accused of engaging in satanic activities.

During the satanic panic of the 1980s, a contemporary legend on satanism was disseminated. It was based on religious propaganda of the Middle Ages (Victor 1998), which claimed that there is a secret sect of devil worshippers that has its own traditions and ritual practices (Lewis 2016). The rhetorical function of the legend of satanic worship was supported by many colorful examples of the actions that were taken by the members of satanic communities. For example, it was said that the satanic communities were involved in necrophily, abused women and children, and sacrificed babies to Satan (DeYoung 1996). Satanic panic has also been interrelated with other moral panics directed at gay people (Falkof 2018), aliens (Paley 1997), the mafia (Albini 1993), and terrorists (Dillinger 2004).

Based on the central assumption of moral panic theory, it could be argued that reference to Satanic ritual abuse (SRA) was instrumental for the theory of moral panic. This means that satanism was only an illustration of moral panic theory and not its foundation. This is the same role that satanism — as a concept — played in the theories of social problem construction. These theories matured in parallel; thus, the theories of moral panic can also be called theories of social problem construction. 
Constructivists, unlike traditionalists, demonstrated the persistent character of satanic

182 practices. For them, the main explanation for satanism was the complex of problems that are

183 present in society (Forsyth \& Olivier 1990). For instance, Furedi (2013) suggested that belief in

184 Satan was a form of conspiracy thinking that emerged as a response to the crisis of causality.

185 Although this explanation uses functionalist logic, I call it constructivist because belief in Satan

186 and the idea of Satan himself are produced (constructed) by people.

187 Theories of social problem construction are still used, as can be confirmed by

188 publications that use their terminology. One example is a dissertation by Kamp(2018), who

189 studied satanism in Zambia. He starts with three hypotheses: evolution, popularity, and mental

190 illness, and he concludes that belief in satanism in Zambia reflected the difficulties that young

191 Zambian Christians faced: the transition to the nuclear family and hierarchical order of society,

192 spiritual insecurity, and doubts about property rights.

193 It could be inferred that theories of moral panic and social problem construction both use

194 the notion of satanism for illustrative purposes. Next, I discuss the role of this concept in the

195 microinterpretative models used to explain satanism.

196 2.1.2 Microinterpretative Sociological Models of Satanism

197 Theories of authority in organizations and dark tourism are microinterpretative models of

198 satanism. The theory of authority in satanic groups is connected with the move from viewing

199 satanists as the products of human fantasies to recognizing philosophical and religious groups

200 that identify themselves as satanic. The scholars who work in this domain use the Weberian

201 theory of authority to explain leadership and management in satanic temples. Researchers have

202 performed participant observations in satanic groups and analyzed their textual materials. 
Alfred (1976) was probably the first to write on satanism, using theories of authority. He

204 conducted his research in the Church of Satan, and he concluded that the charismatic authority of

205 Lavey was based on magic and the natural and social sciences. This was typical for new religious

206 movements, especially Scientology. (A. S. Lavey was the founder of the Church of Satan in the

207 USA.). Since Alfred's work, authority in satanic organizations has been studied by Lewis (2002)

208 and Davies (2016).

209 The theory of authority exploits satanism differently than the macrointerpretations.

210 Scholars who ascribe to it adapt the theory of authority based on empirical evidence and do not

211 treat satanism only as an example. Dark tourism theories are theories of authority connected with

212 attitudes towards satanism and occultism as "normal" phenomena. Light (2017) argued that

213 institutionalized studies of dark tourism started in 1996. This term was coined by Foley and

214 Lennon (Stone and Sharpley, 2008: 576) to refer to the "presentation and consumption of real

215 and commodified death and disaster sites" by visitors (Foley and Lennon, 1996: 198).

216 Sometimes, tourists who visit black metal festivals and the places that are known to be connected

217 with dark magic and satanism are called satanists. However, many reasons might underlie the

218 increasing interest in dark tourism. For instance, Podoshen et al. (2018) conducted a

219 phenomenological analysis of the perceptions formed at black metal festivals, especially at

220 festivals where visitors were forced to feel disgusted and see blood, violence, and different

221 symbols of death. They found that visitors to black metal festivals consider them rituals where

222 they could confront death and overcome their fears connected with it.

223 Microtheoretical interpretations of satanism, in contrast with macrotheories under the

224 same model of satanism, function as an impulse toward the formulation of new theory. Next, I 
225 describe the methodological apparatus that is used by the representatives of the interpretative

226 model. I begin with the macro-level theories and finish with the micro-level theories.

227

228 2.1.3 Methods Used in Interpretative Models of Satanism

229 Theories of moral panic are very distinct from the other theories that belong to the interpretative

230 model because they use diverse methodological approaches. They include qualitative analyses of

231 judicial cases, analysis of argumentation structure in official documents, and analysis of

232 secondary data and the products of mass culture. To a large extent, this is connected with the use

233 of such theories in public discussions about satanism. Most likely, the diversity of methods and

234 use of data helps to make this point of view more convincing. In addition, scholars who use the

235 theory of moral panic tend to choose comparative research designs. For example, DeYoung

236 (1997) analyzed the characteristics of juridical cases connected with satanism in America

237 (DeYoung 1997). This type of data examination can show the scale of the phenomenon and 238 identify factors that engender moral panic.

239 The theories of authority and dark tourism mostly use qualitative methods, such as

240 participant observation at festivals and in organizations, semi-structured interviews, and analysis

241 of secondary data. When these theories were being formed, satanic communities and tourist

242 attractions related to death did not look alike and were not very numerous. Thus, it could be

243 claimed that soft methods were preferred over other methods because researchers were working

244 with small, local, and unique contexts that were not always comparable.

245 To generalize the investigation of interpretative theories on satanism, I comment on the

246 place of satanism in this model and present the limitations of the interpretative model. 
First, reference to satanic ritual abuse is instrumental in the theory of moral panic. This

248 means that satanism was only an illustration of moral panic theory, not its foundation. The theory

249 of authority exploits satanism differently from the macrointerpretations since the latter adapt the

250 theory of authority based on empirical evidence and do not treat satanism only as an example. It

251 should be noted that this model mostly forms reactive and esoteric satanic images, but it does not

252 problematize rationalist satanism.

253 Second, an analysis of their limitations shows that macrointerpretations of the

254 interpretative model could be widely applied, but they should be accompanied by a cautious

255 exploration of the expert field of claim-making, knowledge of the juridical discourse, and the

256 bases of claims that exist in different countries. A researcher cannot access court documents in

257 all countries, so the analysis of microinteractions in the juridical process could be limited.

258 Bearing in mind that satanic moral panic can coexist with the other panics, it is necessary

259 to understand those other social fears (Falkof 2015). The users of this model should consider that

260 the religious context of a country has its own specificities because alternative(s) to satanism

261 could emerge, which could be based on the dominating religious context of the country. The

262 applicability of the theories of satanic authority probably depends on the structure of the satanic

263 group. For example, they might not help analyze decentralized groups. Theories of dark tourism

264 are also context-specific. In particular, they are highly connected with attitudes towards death

265 and dying in a particular country.

266 Third, regarding the power structures that emerge, if the interpretative explanation of

267 satanism is used, it could be argued that satanism is, as claimed by Petersen, "dedemonized."

268 This means that satanism is not represented as a barbarous and criminal activity that is

269 dysfunctional or should be punished. In that model, what is satanic and what is not is defined by 
270 laypeople, not by sociologists. Nevertheless, the model gives voice to nonexpert knowledge. This

271 also diminishes the capacity of sociologists to intervene in explanations of cases that have traits

272 that are analogous to the belief in satanism but not named as such by the people. Next, I analyze

273 the structuralist model of satanism.

274

\section{$275 \quad 2.2$ Structuralist Models of Satanism}

276 Structuralism, in comparison with interpretivism, is not based on the juxtaposition of the natural

277 and social sciences (Devyatko 1996: 35). The representatives of this model seek hidden

278 meanings in people's actions because they suppose that there is a latent orderliness in such things

279 as linguistic behavior, kinship relations, rule-following, and involvement in rituals. The assumed

280 drivers of human behavior are not of a physical or neurophysiological nature; they are structural

281 and cannot be individualized. I classify as structuralist approaches to satanism the explanatory

282 theories of subculture, neotribe, scene, and ideology because they all see satanism as a system of

283 thought, which either has a strict and distinguishable group of adepts or does not have any

284 supporters. If the group of adepts exists, satanism is conceptualized in the microtheoretical sense.

285 My review begins with such theories and concludes with the macrostructuralist ones.

\subsubsection{Microstructuralist Sociological Models of Satanism}

287 Subculture theories, neotribe theories, scene theories, cultural practice theories, and theories of 288 satanism as a social movement belong to the microstructuralist model of satanism. Although

289 alternatives to subculture have been proposed, this concept is still exploited in contemporary

290 studies. Lowney (2016), for instance, used subcultural theory to describe how satanism appeared

291 in the school at Victory Village as a way to oppose the dominant youth culture. The concept of

292 "scene" aimed to replace subcultural, countercultural, and neo-tribal approaches. Researchers 
293 used this concept in relation to satanism in four contexts: "satanic scene" (Dyrendal 2008),

294 "black scene" (Jerrentrup 2000), "gothic scene" (Jerrentrup 2000), and "black metal scene"

295 (Introvigne 2018).

296 Sometimes, satanism is understood as involvement in satanic practices that are ascribed

297 to satanic culture. In connection with such practices, authors propose different classifications of

298 satanists. These studies have practical significance since they often suggest medical and police

299 taxonomies of satanists. Segerberg (1997), for example, describes satanism in Finland and

300 outlines four types of satanists: intergenerational cults, organized satanic churches, solitude

301 satanists, and experimental satanists. Based on these classifications, methods for evaluating

302 personal involvement in satanism were proposed (Damphousse \& Crouch 1992).

303 Understandings of satanism as a social movement should be demarcated from the

304 subcultural perspective because satanism is defined as a group of organizations that are localized

305 in the online and offline spheres. From the social movement perspective, satanism is not

306 necessarily connected with protests against other groups or institutes. For example, Lewis

307 (2002), while working with the definition of satanism as a discursive field, added relations

308 between organizations that adopt satanic ideology.

309 From this brief description of the microstructuralist accounts of satanism, it can be

310 deduced that satanism is used here to illustrate approaches that constitute a larger investigation.

311 2.2.2 Macrostructuralist Sociological Models of Satanism

312 Macrointerpretations of structuralist theories focus on the dynamics of scene practices and

313 ideology. I describe this model with the former.

314 Different from static explanations of scenes, dynamic models have been proposed to

315 explain the reproduction of metal music. The theories of scene practice dynamics assume that 
316 there are differences between the cultural, demographical, and geographical features of the

317 scenes and that these differences can be objectified. These theories are enriching semiotic

318 approaches to the analysis of songs that are created on scenes (Wallach \& Levine 2012: 130). In

319 general, these studies have a quantitative character. For example, Mayer and Timberlake (2014)

320 calculated the percentage of metallic groups in the country. In the theories of scene practices,

321 dynamic satanism is reactive and is based on the formulations of these theories. In the theories of

322 ideology, on the other hand, satanism is considered an illustration. Below, I outline seven

323 conceptualizations of satanism as an ideology, and for some, I provide critical ideas that may be

324 used to counter them.

325 1. Dyrendal and Petersen argued that satanism should be studied as a discursive field 326 (stratified context), which has self-religion, is antinomic, uses words connected with 327 Satan, and has a formulated ideological genealogy usually related to Satan (Petersen 2009). (Self-spirituality is the discourse that was typical of the New Age movement and carries the idea that the "(unenlightened) mass of society are victims of any number of negative habits and beliefs" (Heelas 1999).)

2. Similar to Dyrendal's and Petersen's descriptions are Lap's (2012) descriptions. Lap viewed satanism as self-religion.

3. Faxneld (2017) gave satanism both wide and narrow definitions. The narrow definition considers it a system with Satan as its leader. The wide definition, in contrast, states that satanism is a discursive strategy. Using satanism in black metal has become a very popular subject among scholars. However, they differ from each other because of their countries of origin and approaches to discourse analysis. 
4. Satanism as magic was defined by Marcello Truzzi (Petersen 2005). He placed groups of satanists on the black-white magic continuum.

5. Introvigne (2016) suggested that satanism is a personality cult, where a person is worshipped through ritual practices by an organized group identified with Satan or Lucifer which has minimal hierarchy and organization.

6. Van Lujk (2016) understood satanism as intentional Satan worship based on religious motives. He contradicted Introvigne's definition of satanism because he considers it too strict. Van Lujk preferred to exclude formal organizations from the definition (Van Luijk 2016), and he distinguished between attributed satanists and identified satanists.

7. Granholm (2012), in contrast to the other six approaches, proposed that satanism be deleted from academic discourse. Instead, he suggested such notions as "Postsatanism" and "Left-Hand path." He saw these notions as more suitable for scientific discourse because they helped to combine an etic and emic understanding of satanism in scholarly discourse (Petersen 2016: 87). Among these approaches, I mentioned Granholm because his conceptualization was based on a skeptical analysis of the adequacy of such a term for social scientific investigations. As a result, his proposed terminology also frames satanism as an ideology.

\subsubsection{Methods Used in Structuralist Models of Satanism}

Structuralism differs greatly from interpretivism in terms of cross-country comparisons. In the structuralist articles, one may find comparisons of 150 to 200 countries. Indeed, the structuralist model uses quantitative methods of analysis such as regression. However, the use of quantitative methods is typical only for the small group of theories that exist in structuralism (theories of 
361 scene dynamics). Other approaches are not prone to use quantitative methods, as they mostly

362 work with textual data and employ ethnography. Although the structural model of satanism is

363 quite heterogeneous, some conclusions can be drawn from it.

364 First, this model, like the interpretative model, treats "satanism" in a dual way. Some

365 authors wanted to use satanism to exemplify their theories, while other theories were based on

366 empirical analyses of satanism. This model accounts for all three types of satanic discourses.

367 Second, it should be said that this model, apart from helping to discover local

368 organizational and textual forms of satanism, diminishes the agency of those forms.

369 Underestimating the intentionality of individual actors is possible because of the overestimation

370 of the role of written sources, language, and symbols. It is possible that the interpretative

371 approach, as an addition to the structuralist, could reduce the latter's drawbacks.

372 Third, the structuralist approach sees satanism mostly as a neutral phenomenon. Only

373 cultural practice theory, being close to criminalistics, creates negative connotations. However,

374 the power of naming something as satanic in this model is mostly given to sociologists. Although

375 this ability to control strengthens sociological authority, it could limit critical reasoning. The last

376 model of satanism that I distinguished is the functionalist model, which I analyze next.

\section{$377 \quad 2.3$ Functionalist Models of Satanism}

378 Functionalist models in sociology are concerned with interpreting the goals of actions (Devyatko

379 1996: 37-38). Those goals are not always known by the people who take certain actions. Usually,

380 functionalist explanations are connected with the survival of societies, cultures, or social

381 institutions. However, the explanations can also be microsocial and apply to processes on the

382 individual level. This is true, for instance, for psychoanalytical explanations that are based on

383 people's unconscious motives. 
Functionalist explanations of satanism in sociology are scarce. I delineate two types:

385

386

387

388

389

390

391

392

393

394

395

396

397

398

399

400

401

402

403

404

405

406

exorcism as a means to control social life and the use of satanic discourse in historical and cultural contexts. These theories were developed to explain the reasons for the appearance of satanic topics in social discussions. In these discussions, constructivism is closer to functionalism because satanism and exorcism are analyzed separately as inventions of the social system and as natural and necessary for it. Functionalist models work, mostly, in the US context. Therefore, they should show the universal character of the functions of satanism and exorcism, and these works also tend to make between-country comparisons.

Two of the most noticeable models of satanism in the functionalist approach were proposed by Introvigne and Petersen. Introvigne (2016) examined satanism before its modern form of existence, while Petersen (2005) addressed contemporary satanism. While looking at the social history of satanism, Introvigne noticed a significant change in attitudes toward satanism.

Pro-satanic attitudes always alternated with anti-satanic attitudes. Introvigne applied this model to different historical periods: proto-satanism, anti-modern satanism, and contemporary satanism. Petersen discussed only the development of contemporary satanism. He identified three stages. The first stage was the formation of the Church of Satan. The second stage was connected with the appearance of the Temple of Set. The third stage was characterized by the rise of satanic activity in the Internet sphere. It is claimed that the Internet helped satanists popularize their ideology and sustain long-distance communication.

Exorcism, as a way to protect life from the devil, was extensively studied by Giordan and Possamai (2018). I mention investigations of exorcism in connection with research on satanism because the scholars who study this topic stated that people who believed in possession attributed this to satanists. Therefore, those scholars claimed that those involved in exorcism believed in 
407 Satan's existence and satanism, and they defined satanism as the service of Satan. Studies of

408 exorcism in this area of scholarship can be categorized under functionalism because defending

409 oneself against Satan means that the person believes in Satan. In the past, exorcism could serve

410 as a moral compass. This means that it helped a person understand the difference between right

411 and wrong. Some argued that exorcism is not actual, but because of mass culture, faith in

412 exorcism has increased. De Corto has tried to explain these changes in the popularity of

413 exorcism. He claimed that exorcism was more likely to emerge when there is a struggle between

414 different religious groups and science, and science is not the winning side.

415 Exorcism also played a role in the training of Catholic priests (Sluhovsky 2002).

416 Exorcism illustrated the difference in power between legal specialists and exorcists. Howe and

417 Ferber (2005) showed how the Australian government used the case of murder by exorcism to 418 enforce their expert power in the definition of exorcism.

\section{2.3.1 Methods Used in Functionalist Models of Satanism}

420 The methodology used in functionalism is mostly sociohistorical. Those studies analyze the

421 reception of satanism or the profession of the exorcist, and the authors prefer to analyze archival

422 data and the results of other studies to explain the functions of satanism and exorcism.

423 Before discussing the lack of a naturalist model of satanism in sociology, some

424 conclusions should be presented on the functionalist model of satanism in sociological discourse.

425 First, from a functionalist perspective, satanism is usually the origin of a certain

426 conception or formulation. All three discourses on satanism-reactive, esoteric, and rationalist-

427 are represented in the functionalist logic, and their appearance on the societal level is explained

428 by diverse macroprocesses such as maintaining equilibrium in the social system. 
Second, the ultimate benefit of the functionalist approach is its basis in the historical

430 context. However, the periods outlined by the authors tend to show the "average" situation in the

431 world, and they depend on the peculiarities of the country on which they were constructed, such

432 as the configuration of the court system or the political system.

433 Third, satanism is depicted as a neutral phenomenon in the functionalist account. The

434 ability to name something satanic belongs both to the sociologist and to the object of

435 investigation. Therefore, in terms of power structures, this model is quietly balanced, probably

436 because of the historical comparisons and periodizations that are made. However, as has already

437 been seen in this historical examination, an orientation may be based on one particular case,

438 which can lead to an intentional or unintentional judgment of other cases based on the one that is

439 used as a sample.

\section{$440 \quad 2.4$ Naturalist Models of Satanism}

441 A critical conceptual analysis, distinct from investigations of the existing modes of knowledge

442 production on a certain topic, is supposed to seek knowledge that does not yet exist. This means

443 that if there are supposed to be four models of a certain thing and one model is missing, we

444 should think about the reasons for the omission and try to reconstruct the missing model. Among

445 the outlined models for satanism in sociology, there are no naturalistic explanations. However, a

446 close examination of psychological approaches to studying satanism could help to create an

447 image of the naturalist account of satanism. The naturalist model in the social sciences is not

448 very different from the methods of the natural sciences in its treatment of the methods, nature,

449 and goals of the object of study (Devyatko 1996: 9).

450 In theological psychology and psychotherapy, there is a concept called the "satanic

451 syndrome." This approach can be considered the closest to naturalism. The satanic syndrome 
452 includes symptoms such as taking part in satanic rituals, engaging in communication with dead 453 people, studying scholarship on black magic, membership in the occult community, and reading

454 books and journals devoted to occultism and esoterism. One psychologist-theologist, Šram

455 (2017), claimed that people with high values on scales of psychopathy and depression are more

456 prone to the satanic syndrome. Šram tested his hypotheses on a Croatian sample and found

457 correlations among psychopathy, depression, and satanic syndrome in both genders and different 458 ethnic groups.

459 Psychoanalytical and psychodynamic approaches in psychology are closer to structural-

460 functionalist explanations of satanism because satanism is viewed as a dysfunction of the family

461 and different agents of socialization.

462 In psychoanalysis, satanism is associated with obsessions with demons (Ivey 1993). It is

463 recommended that psychiatric work with victims of satanism focus on the analysis of memories

464 of their relations with their fathers in childhood (Corbett 2018). It is supposed that the father was

465 not successful in his role as a parent because this child chose another father-Satan. Some

466 psychologists have refuted the connection between behaviorism and satanism (Barrett 2012).

467 Philosophy and psychoanalysis are sometimes combined to analyze representations of

468 satanism in mass culture ${ }^{2}$. For example, Hicks (2017), using the Delesian conception of

469 masochism, examined relations between the mother and child in the movie "Rosemary's Baby."

470 Satanism has also been studied as a set of religious ideas connected with different stigmatized

471 behaviors, such as self-harm (Csordas \& Jenkins 2018).

472 In psychological discourse on satanism, this concept is mostly seen as reactive. People

473 who are associated with it are represented as needing professional help. Based on this view of

\footnotetext{
${ }^{2}$ By researching the satanists appearance of Satan and satanists in mass media, the scholars say that they study satanism as the producers of the show and the characters name the product presented in the media as satanism.
} 
474 satanism, an analogical sociological account could be constructed. However, with such benefits

475 as understanding the social predispositions to being named satanic or a Satanist, such a

476 sociological approach risks discounting the influence of social forces on the person or group that

477 is named satanic.

478 In the last part of this article, I present the connections between the distinct sociological

479 models of satanism.

\section{Relations Between Sociological Models}

481 From the figures on the relations between models (Figs. 1-5), some conclusions on the structure 482 of these relations can be drawn.

\section{$483 \quad 3.1$ Diversity}

484 There are different ways to form relations between the examined theories. Some theories can 485 enter all types of relations with the other theories, while others have a limited quantity of 486 relations. The more various the relations, the less possibility the theory could be integrated with 487 the others.

Only two types of relations use exorcism as a mode of social life control: elaboration and

489 integration. This means that there are heuristic capacities that exist for this theory, and a

490 competing theory, variant, or subtheory could emerge. However, the abilities in terms of theory

491 formation are very limited for scene practice dynamics, ideology, and satanic discourse reception

492 in historical and cultural contexts. These theories have already established relations with the

493 others. Nevertheless, intersections between the models should not be ignored.

494 There is a tendency to build certain forms of relations within the theories of the same

495 model. Our figures demonstrate that tendency: competitive and prolific relations are often

496 constructed with theories that are not included in the same model. Based on this observation, it 
497 could be argued that - both for the theories with the most relation-type diversity and for those

498 with less - there is the potential to expand the explanations through further proliferation and

499 competition. For instance, we could think of the proliferation of exorcism as a way of social life

500 control and dark tourism theory. In that case, the will of the person to visit a certain showplace is

501 functional for the person's moral socialization.

\section{Conclusion and Discussion}

503 In sociology and the other social sciences, many concepts have nonscientific origins. Satanism is

504 one term that emerged in Catholic writings and entered sociology through the constant social

505 usage of the term. Including this notion in sociology has provoked different reactions from

506 scholars about the appropriateness of this term for sociological inquiries. Some academics have

507 argued that this notion reproduces the oppressive circumstances in which the term emerged.

508 Others have claimed that sociological discourse frames satanism as a normal phenomenon and

509 demarcates itself from lay discourse of the topic. Furthermore, temporal models have been

510 suggested to show that attitudes toward the concept of satanism in the social sciences have not

511 always been the same.

512 The critical concept analysis of the sociological scholarship on satanism in this article

513 identified multiple models of satanism, even from a static perspective. Three dominant models

514 were identified: interpretative, structuralist, and functionalist. This corresponds with the idea of

515 the heterogenization of the current discourse on the scientific study of satanism suggested by

516 Petersen (2014). Recent research in all three discourses on satanism is investigated, and there are

517 studies that belong to the different models, not just the dominant one. The lack of a naturalist

518 explanation of satanism in sociology also was explored. I presented examples from an adjacent

519 discipline (psychology) to show that this perspective on satanism also is possible. 
Furthermore, it cannot be said that satanism is framed positively in most sociological

521 discourse, as Taub and Nelson (1993) claimed. In all the models, satanism is shown as both

522 barbarous and peaceful. It was clear that the "negative" image of satanism appeared in

523 interpretivism when satanism was used in the implementation of social policy. Thus, Fitzgerald

524 was right when he argued that religion goes hand in hand with politics. This explanation of

525 satanism provided a place for actors in legal, religious, political, and social movements to

526 establish power, and medicine and psychology, along with psychiatry, became involved in the

527 discursive battles. In addition, a negative frame for satanism could be developed in the naturalist

528 model of satanism if it existed. In structuralism and functionalism, satanism is discussed both

529 positively and neutrally, except for the theory of cultural practices, which are tightly connected

530 with criminological needs.

531 It could be argued that in sociology, satanism is not completely demarcated from its lay

532 conceptualizations. In the interpretative model, the meanings that agents create around satanism

533 are considered by sociologists, especially in the theories of moral panic and social problem

534 construction. Taub and Nelson's (1993) continuum of discourse in such a situation should have

535 more axes and should not juxtapose "establishment" satanism with "underground" satanism.

536 There are several conceptualizations of satanism that form relations with each other and

537 create possibilities for new approaches to study satanism. As for my own view of present efforts

538 to explain satanism, I agree with scholars like McKinnon (2002) who identify the multiplicity of

539 meanings attributed to fundamental concepts in religious studies that we should dispense

540 altogether with satanism as a scientific notion. Instead, we could try to explore the naturalistic

541 model to explain satanism that was underdeveloped in sociology, however not without certain

542 sacrifices. On the one hand, a naturalistic explanation of satanism could avoid the negative and 
543 positive framings of satanism, as this concept is value-laden from the beginning. Moreover,

544 naturalistic approaches to defining concepts usually presuppose rather strict ways to

545 operationalize and measure. So, any blurred concept of satanism is likely to be avoided. On the

546 other hand, such models do not consider lay people's assumptions on satanism, so they reify,

547 linguistically instrumentalize, and essentialize the concept ${ }^{3}$. Furthermore, it should not be

548 forgotten that when we make something more calculable and measurable, we also make it easier

549 to control and sanction that phenomenon from outside the academy by different social actors and

550 responsible actions. Finally, a naturalistic model of satanism should not presuppose the rejection

551 of the other models. It is wiser to exploit the naturalist explanation in a pragmatic manner (Blum,

552 2011) as a complementary one to the others.

\section{Limitations}

554 This analysis was limited because only papers in English were examined, and I analyzed only 555 papers that were published from 1918 to 2018. There are several ways in which future research 556 could improve on this study. First, propositions for the functionalist approach to satanism could 557 be developed. Second, sociological discourse on satanism could be compared with the discourse 558 from other disciplines and with lay discourse, as done by Taub and Nelson (1993). Third, a 559 comparison of the sociological discourse on satanism in different countries could be conducted 560 to consider the cultural specifics of sociological scholarship in those countries.

\footnotetext{
${ }^{3}$ See Bevir and Kedar (2008) about problems in concepts formation in the naturalist model.
} 
562

563

564

565

566

567

568

569

570

571

572

573

574

575

576

577

578

579

580

581

582

583

584

\section{References}

Abbott, Andrew (2004). Methods of Discovery: Heuristics for the Social Sciences. New York: Contemporary Societies Series.

Albini, Joseph L. (1993). The mafia and the devil: What they have in common. Journal of Contemporary Criminal Justice 9 (3), pp. 240-250.

Alfred, Randall H. (1976). The church of satan. In: C. Y. Glock \& R. N. Bellah (eds.), The New Religious Consciousness, Berkeley: University of California Press, pp. 180-202

Asprem, Egil (2016). Reverse-engineering 'esotericism': How to prepare a complex cultural concept for the cognitive science of religion.Religion 46 (2), pp. 158-185.

Barrett, Louise (2012). Why behaviorism isn't satanism. In: J. Vonk \& T. K. Shackelford (eds.), The Oxford Handbook of Comparative Evolutionary Psychology, Oxford: Oxford University Press, pp. 17-38.

Berenskoetter, Felix (2017). Approaches to concept analysis. Millennium 45 (2), pp. 151-173.

Berger, Joseph, Dana P. Eyre, \& Morris Zelditch (2018). Theoretical structures and the micromacro problem. In: J. Berger \& M. Zelditch (eds.), Status, Power, and Legitimacy: Strategies \& Theories, New Brunswick: Transaction Publishers, pp. 55-70.

Blum, Jason. (2011). Pragmatism and Naturalism in Religious Studies. Method \& Theory in the Study of Religion, 23(2), pp. 83-102.

Bromley, David G. (1991). The satanic cult scare. Society 28 (4), pp. 55-66.

Corbett, Lionel (2018). Understanding Evil: A Psychotherapist's Guide. Abingdon: Taylor \& Francis.

Cree, Viviene, Gary Clapton, \& Mark Smith (2015). Revisiting Moral Panics. Bristol: Policy Press. 
585 Csordas, Thomas J. \& Janis H. Jenkins (2018). Living with a thousand cuts: Self-cutting, agency, 586 and mental illness among adolescents. ETHOS 46 (2), pp. 206-229.

587 Damphousse, Kelly R. \& Ben M. Crouch (1992). Did the devil make them do it? Youth \& Society $24(2)$, pp. 204-227.

Davies, Maxwell (2016). Self-conscious routinization and the post-charismatic fate of the church of satan from 1997 to the present. In: J. A. Petersen (ed.), Contemporary Religious Satanism, Abingdon: Routledge, pp. 87-96.

Devyatko, Inna F. (1996). Modeli Obyasneniya i Logika Sotsiologicheskogo Issledovaniya. RCHO-TEMPUS / TASIS.

DeYoung, Mary (1996). Speak of the devil: Rhetoric in claims-making about the satanic ritual abuse problem. Journal of Sociology and Social Welfare 23, pp. 55.

DeYoung, Mary (1997). Satanic ritual abuse in day care: An analysis of 12 American cases. Child Abuse Review 6 (2), pp. 84-93.

Dillinger, Johannes (2004). Terrorists and witches: Popular ideas of evil in the early modern period. History of European Ideas 30 (2), pp. 167-182.

Dyrendal, A., James R. Lewis, \& Jesper A. Petersen (2015). The Invention of Satanism. Oxford: Oxford University Press.

Dyrendal, Asbjørn (2008). Devilish consumption: Popular culture in satanic socialization. Numen 55 (1), pp. 68-98.

Falkof, N. (2015). Satanism and Family Murder in Late Apartheid South Africa: Imagining the End of Whiteness. London: Palgrave.

Falkof, Nicky (2018). Sex and the devil: Homosexuality, satanism, and moral panic in late apartheid South Africa. Men and Masculinities 22 (2), pp. 273-293. 
608 Faxneld, Per (2017). Satanic Feminism. Oxford: Oxford University Press.

609 Fitzgerald, Timothy (2015). Critical religion and critical research on religion: Religion and politics as modern fictions. Critical Research on Religion 3 (3), pp. 303-319.

611 Foley, Malcolm, and J. John Lennon (1996). "JFK and Dark Tourism: A Fascination with Assassination.” International Journal of Heritage Studies 2, no. 4 (December 1996): pp.

Forsyth, Craig J. \& Marion D. Olivier (1990). The theoretical framing of a social problem: Some $198-211$. conceptual notes on satanic cults. Deviant Behavior 11 (3), pp. 281-292.

Frankfurter, David (2001). Ritual as accusation and atrocity: Satanic ritual abuse, gnostic libertinism, and primal murders. History of Religions 40 (4), pp. 352-380.

Furedi, Frank (2013). Modern demonology: Ritual abuse, conspiracy and cover-up. In: F. Furedi (ed.), Moral Crusades in an Age of Mistrust: The Jimmy Savile Scandal, London: Palgrave, pp. 66-80.

Giordan, Giuseppe \& Adam Possamai (2018). The sociology of exorcism. In: G. Giordan \& A. Possamai (eds.), Sociology of Exorcism in Late Modernity, Switzerland: Springer International Publishing, pp. 21-40.

Granholm, Kennet (2012). The left-hand path and post-satanism. In: P. Faxneld (ed.), The Devil's Party: Satanism in Modernity, Oxford: Oxford University Press, pp. 289.

Heelas, Paul (1999). De-traditionalisation of religion and self: The new age and postmodernity. In: K. Flanagan \& P. C. Jupp (eds.), Postmodernity, Sociology and Religion, London: 
631 Hicks, Charles (2017). The perverse mother: Maternal masochism in Ira Levin's Rosemary's Baby. Hypatia 32 (2), pp. 296-311.

633 Holt, Cimminnee (2012). Satanists and Scholars: A Historiographic Overview and Critique of 634 Scholarship on Religious Satanism. Master's Thesis. Quebec: Concordia University.

635 Howe, Adrian \& Sarah Ferber (2005). Delivering demons, punishing wives. Punishment \& Society 636 (2), pp. 123-146.

637 Introvigne, Massimo (2016). Satanism: A Social History. Leiden: Brill.

638 Ivey, Gavin (1993). The psychology of satanic worship. South African Journal of Psychology 23

639 (4), pp. 180-185.

640 Jerrentrup, Ansgar (2000). Gothic and dark music: Forms and background. The World of Music 42 $641 \quad(1)$, pp. $25-50$.

642 Kamps, Johanneke (2018). Speaking of Satan in Zambia: The Persuasiveness of Contemporary 643 Narratives About Satanism. Utrecht: Utrecht University.

644 Lap, Amina O. (2012). Categorizing modern satanism. In: P. Faxneld \& J. A. Petersen (eds.), The 645 Devil's Party, Oxford: Oxford University Press, pp. 83-102.

646 Lewis, James R. (2002). Diabolical authority: Anton lavey, the satanic Bible and the satanist 647 "tradition". Marburg Journal of Religion 7 (1), pp. 1-16.

648 Lewis, James R. (2016). Satanic ritual abuse. In: J. R. Lewis \& I. B. Tollefsen (eds.), The Oxford 649 Handbook of New Religious Movements, Oxford: Oxford University Press, pp. 210.

650 Light, Duncan (2017). Progress in dark tourism and thanatourism research: An uneasy relationship 651 with heritage tourism. Tourism Management 61, pp. 275-301.

652 Lowney, Kathleen (2016). The devil's down in Dixie: Studying satanism in South Georgia. In: J. 653 A. Petersen (ed.), Contemporary Religious Satanism, Abingdon: Routledge, pp. 115-130. 
654 Lynch, Thomas (2017). Social construction and social critique: Haslanger, race, and the study of

655

656

657

658

659

660

661

662

663

664

665

666

667

668

669

670

671

672

673

674

675 religion. Critical Research on Religion 5 (3), pp. 284-301.

McKinnon, Andrew (2002). Sociological definitions, language games, and the" essence" of religion. Method \& Theory in the Study of Religion 14(1), pp. 61-83.

Mayer, Adam \& Jeffrey M. Timberlake (2014). "The fist in the face of god": Heavy metal music and decentralized cultural diffusion. Sociological Perspectives 57 (1), pp. 27-51.

Paley, J. (1997). Satanist abuse and alien abduction: A comparative analysis theorizing temporal lobe activity as a possible connection between anomalous memories. British Journal of Social Work 27 (1), pp. 43-70.

Petersen, J.A. (2009). Contemporary Religious Satanism: A Critical Anthology. Surrey: Ashgate Publishing, Ltd.

Petersen, Jesper (2014). Bracketing Beelzebub: Introducing the academic study of satanism. International Journal for the Study of New Religions 4 (2), pp. 161-176.

Petersen, Jesper A. (2005). Modern satanism: Dark doctrines and black flames. In: J. R. Lewis \& J. A. Petersen (eds.), Controversial New Religions, Oxford: Oxford University Press, pp. 423-457.

Petersen, Jesper A. (2016). Embracing others than satan: The multiple princes of darkness in the left-hand path milieu. In: J. A. Petersen (ed.), Contemporary Religious Satanism, Abingdon: Routledge, pp. 97-114.

Podoshen, Jeffrey S., Grace Yan, Susan A. Andrzejewski, Jason Wallin, \& Vivek Venkatesh (2018). Dark tourism, abjection and blood: A festival context. Tourism Management 64, pp. 346-356. 
676 Ritzer, George (1975). Sociology: A multiple paradigm science. The American Sociologist 10 (3), pp. 156-167.

678 Ritzer, George, Shanyang Zhao, \& Jim Murphy (2001). Metatheorizing in sociology: The basic 679 parameters and the potential contributions of postmodernism. In: J. H. Turner (ed.), Handbook of Sociological Theory, Boston: Springer, pp. 113-131.

681 Robinson, Benjamin G. (2019). Racialization and modern religion: Sylvia wynter, black feminist 682 theory, and critical genealogies of religion. Critical Research on Religion 7 (3), pp. 257 274. 1379-1411.

Šram, Zlatko (2017). Psychopathy and depression as predictors of the satanic syndrome. Open Theology 3 (1), pp. 90-106.

Stone, Philip, and Richard Sharpley (2008). Consuming Dark Tourism: A Thanatological Perspective. Annals of Tourism Research 35, no. 2 (April 1, 2008): 574-95. Clinical Forensic Medicine 4 (4), pp. 188-191.

Sluhovsky, Moshe (2002). The devil in the convent. The American Historical Review 107 (5), pp.

Segerberg, Margaretha (1997). Satanic abuse, with focus on the situation in Finland. Journal of $1379-1411$.

Stam, Zlatt


699 Wallach, Jeremy \& Alexandra Levine (2012). 'I want you to support local metal': A theory of metal $700 \quad$ scene formation. Popular Music History 6, pp. 119-139.

701 White, Ethan D. (2017). Sympathy for the devil: A review of recent publications in the study of 702 satanism. Correspondences 5, pp. 95-112.

703 


\section{Tables}

Table 1. Models of explanations of satanism in sociology.

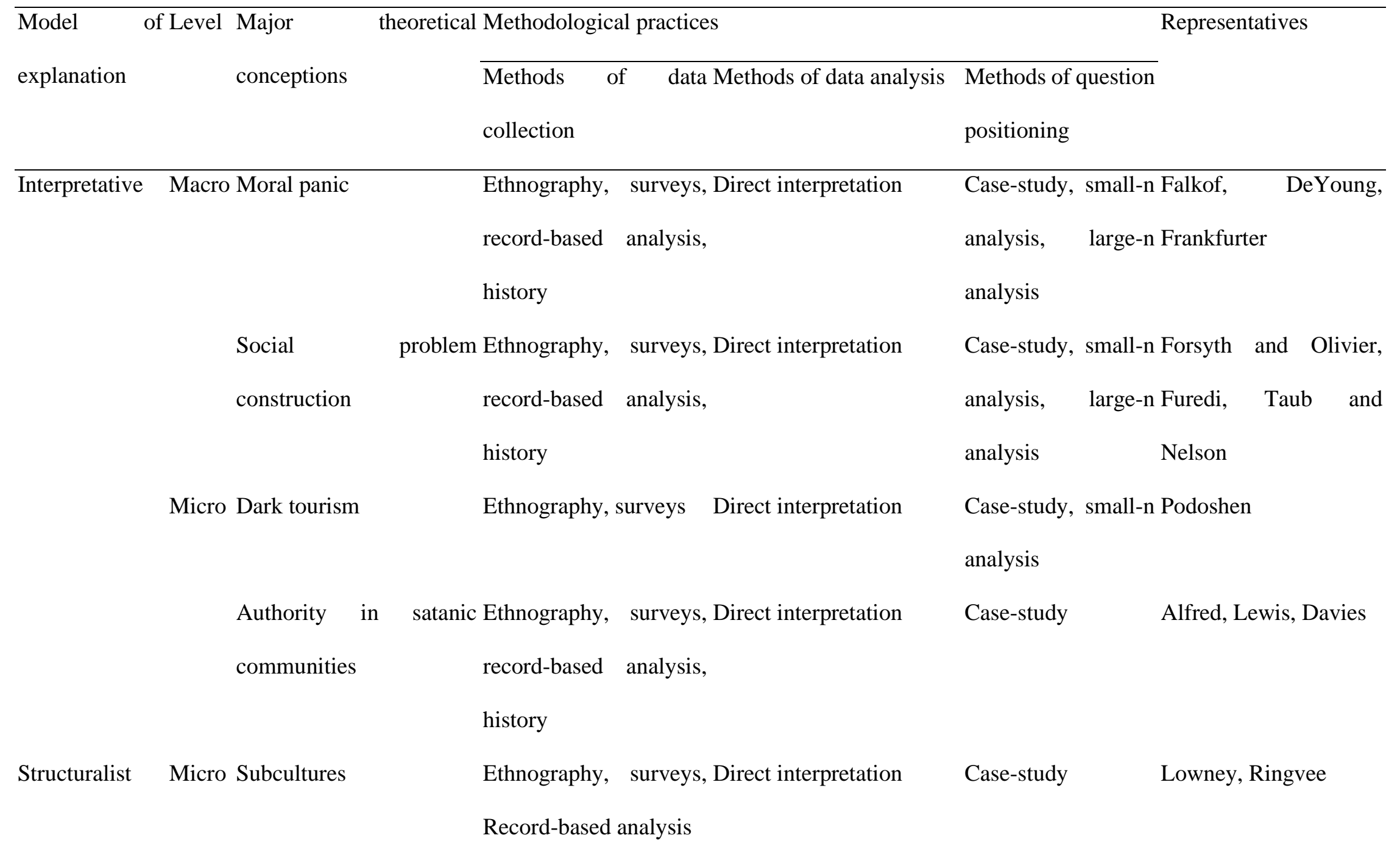




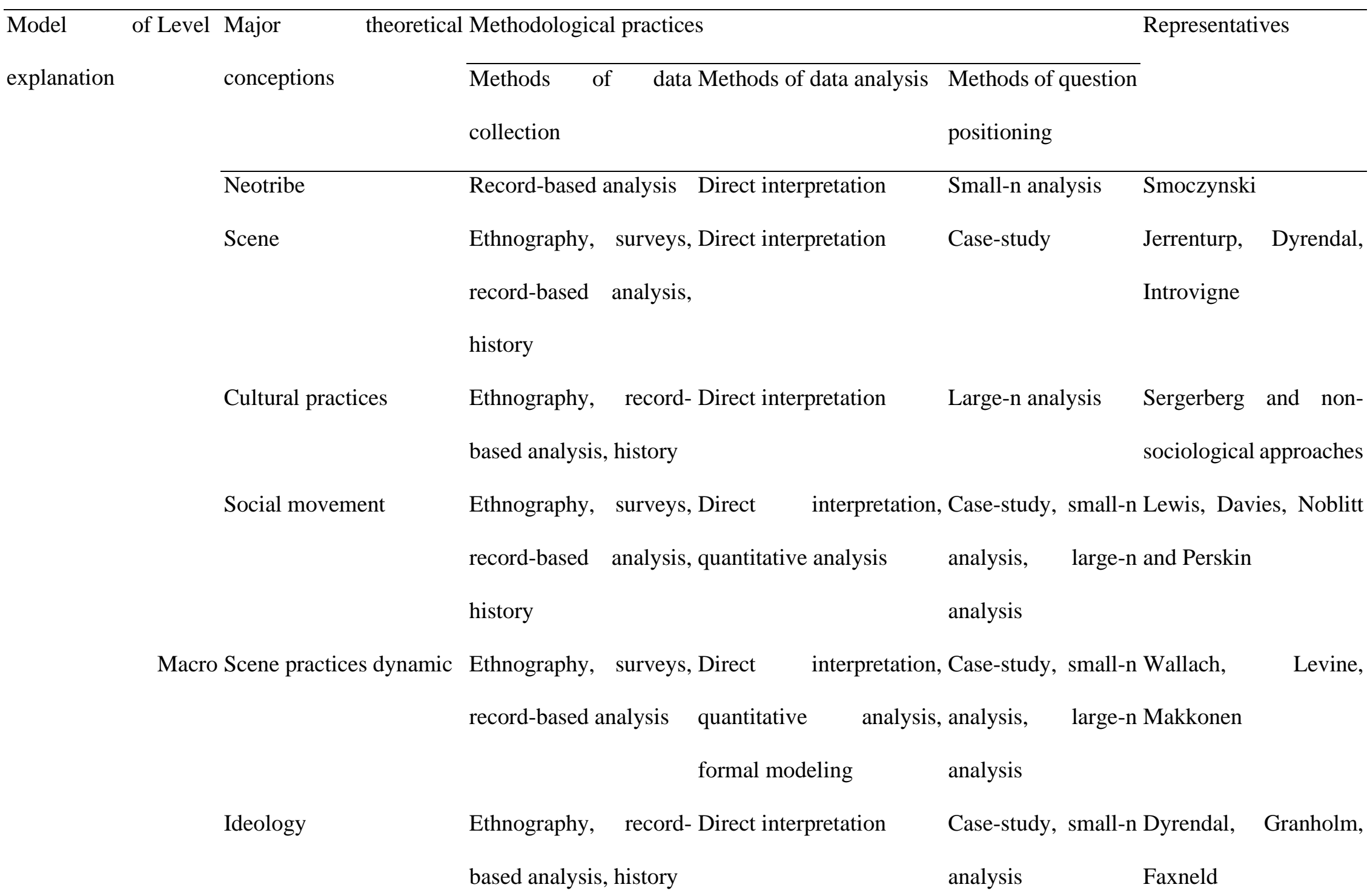




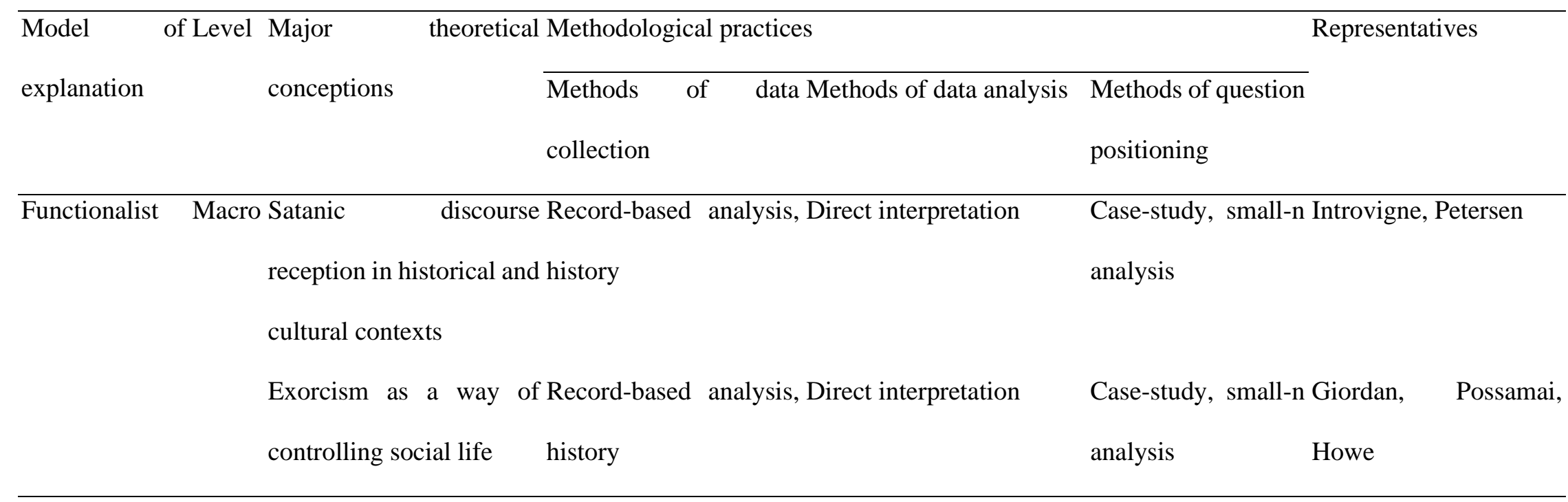




\section{Figures}

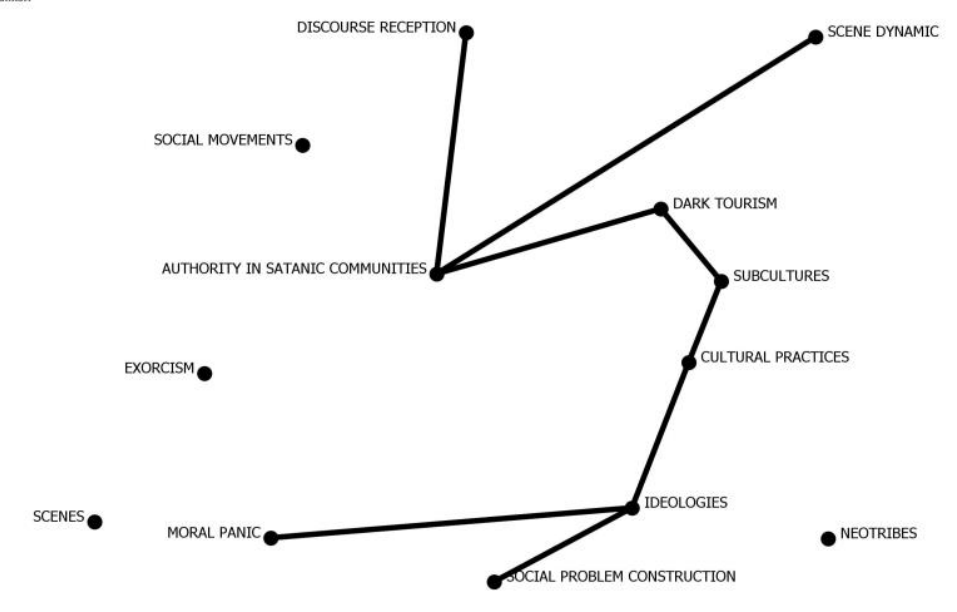

Fig. 1. Prolific relations between theoretical explanations of satanism ${ }^{4}$.

${ }^{4}$ The nodes are theoretical explanations of satanism, and the links symbolize prolific relations between these theories. Two nodes are linked if their theoretical conceptions of satanism are in prolific relations with each other. In this figure, such conceptions as scenes, neotribes, social movements, and exorcism are not in prolific relations with any of the others. However, two conceptions could be called leaders in terms of the number of prolific relations in which they are involved. Authority in satanic communities and ideologies have three such relations each. The figure is constructed on the basis of a theoretical matrix. In the future, this network of relations might be analyzed using methods of social network analysis (SNA). This means that the measures of centralities could be calculated and structural coefficients that characterize this network. However, in this paper I have not included such calculations to not burden the text. 


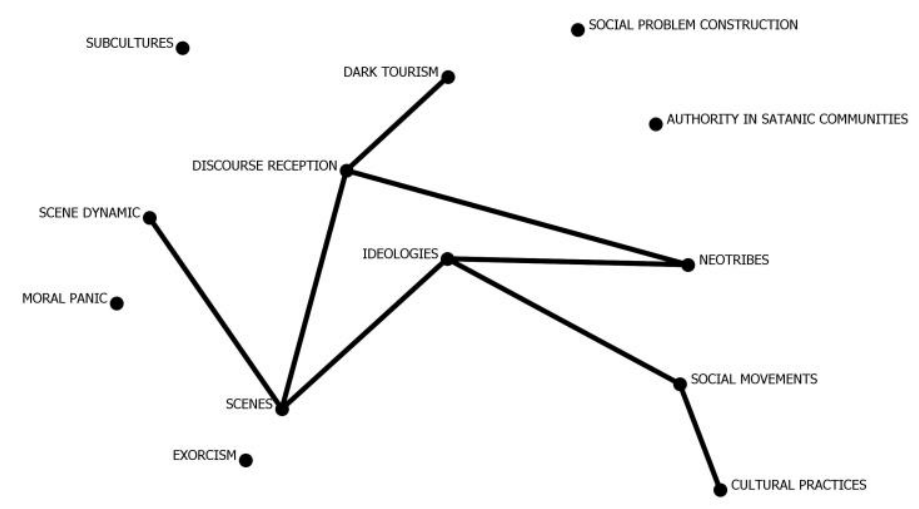

Fig. 2. Variant relations between theoretical explanations of satanism ${ }^{5}$.

${ }^{5}$ The nodes are theoretical explanations of satanism, and the links symbolize the variant relations between these theories. Two nodes are linked if their theoretical conceptions of satanism are in variant relations with each other. In this figure, subcultures, moral panic, exorcism, authority in satanic communities, and social problem construction are not in variant relations with any of the others. However, three conceptions could be called leaders in terms of the number of variant relations in which they are involved. Scenes, ideologies, and discourse reception have three connections each with other conceptions. The figure is constructed on the basis of a theoretical matrix. In the future, this network of relations might be analyzed using methods of social network analysis (SNA). This means that the measures of centralities could be calculated and structural coefficients that characterize this network. However, in this paper I have not included such calculations to not burden the text. 


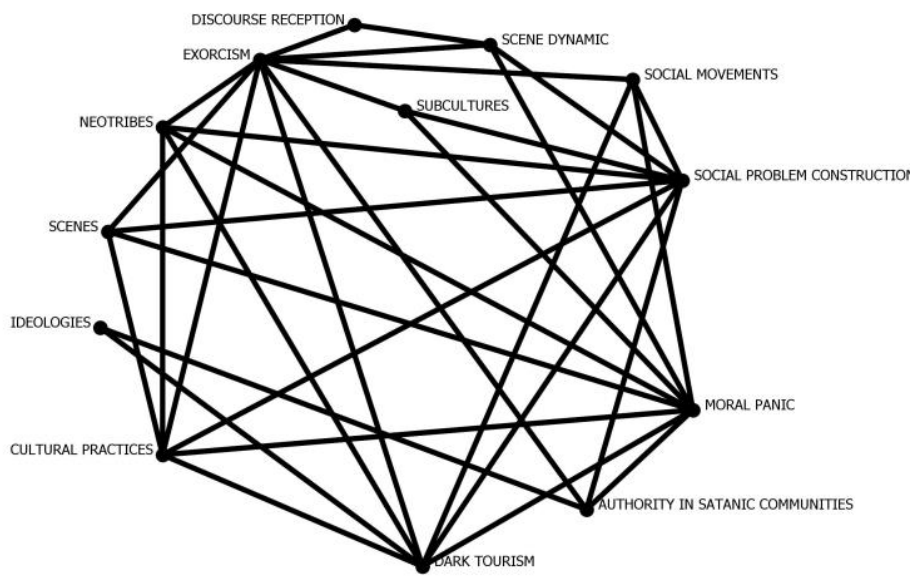

Fig. 3. Competitive relations between theoretical explanations of satanism ${ }^{6}$.

${ }^{6}$ The nodes are theoretical explanations of satanism, and the links symbolize the competitive relations between these theories. Two nodes are linked if their theoretical conceptions of satanism are in competitive relations with each other. In this figure, all the conceptions are in some competitive relations with the others. However, two conceptions could be called leaders in terms of the number of competitive relations in which they are involved. Moral panic and exorcism have eight such relations each The figure is constructed on the basis of a theoretical matrix. In the future, this network of relations might be analyzed using methods of social network analysis (SNA). This means that the measures of centralities could be calculated and structural coefficients that characterize this network. However, in this paper I have not included such calculations to not burden the text. 


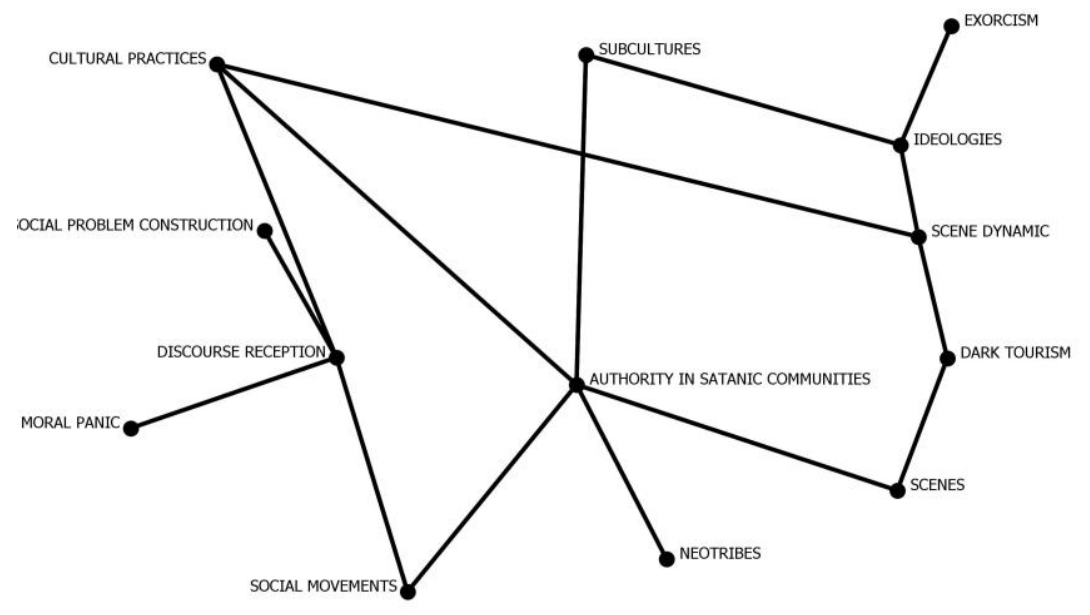

Fig. 4. Integrative relations between theoretical explanations of satanism ${ }^{7}$.

${ }^{7}$ The nodes are theoretical explanations of satanism, and the links symbolize the integrative relations between these theories. Two nodes are linked if their theoretical conceptions of satanism are in integrative relations with each other. In this figure, all the conceptions are in some integrative relations with the others. However, there is one conception that could be called a leader in terms of the number of integrative relations in which it is involved. Authority in satanic communities is connected with five other theories. The figure is constructed on the basis of a theoretical matrix. In the future, this network of relations might be analyzed using methods of social network analysis (SNA). This means that the measures of centralities could be calculated and structural coefficients that characterize this network. However, in this paper I have not included such calculations to not burden the text. 


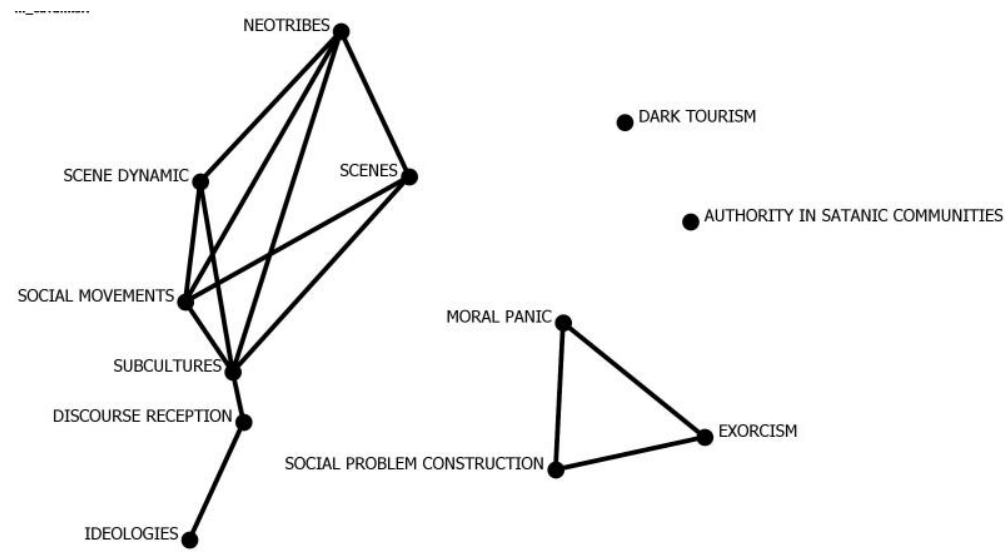

- CULTURAL PRACTICES

Fig. 5. Development relations between theoretical explanations of satanism ${ }^{8}$.

${ }^{8}$ The nodes are theoretical explanations of satanism, and the links symbolize the development relations between these theories. Two nodes are linked if their theoretical conceptions of satanism are in developmental relations with each other. In this figure, dark tourism, authority in satanic communities, and cultural practices are not in development relations with any of the others. However, there are also three conceptions that could be called leaders in terms of the number of developmental relations in which they are involved. Social movements, subcultures and neotribes have four connection each with other conceptions. The figure is constructed on the basis of a theoretical matrix. In the future, this network of relations might be analyzed using methods of social network analysis (SNA). This means that the measures of centralities could be calculated and structural coefficients that characterize this network. However, in this paper I have not included such calculations to not burden the text. 